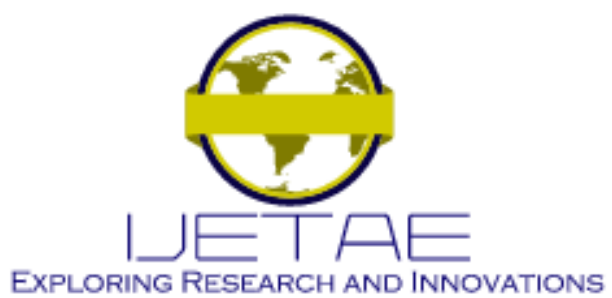

International Journal of Emerging Technology and Advanced Engineering

Website: www.ijetae.com (E-ISSN 2250-2459, Scopus Indexed, ISO 9001:2008 Certified Journal, Volume 12, Issue 02, February 2022)

\title{
Drone-based Geographical Information System (GIS) Mapping of Cassava Pythoplasma Disease (CPD) for Precision Agriculture
}

\author{
Irma T. Plata ${ }^{1}$, Edward B. Panganiban ${ }^{2}$, Darios B. Alado ${ }^{3}$, Allan C. Taracatac ${ }^{4}$, Bryan B. Bartolome ${ }^{5}$, \\ Freddie Rick E. Labuanan ${ }^{6}$ \\ ${ }_{1,2,3,4,5,6}$ CCSICT, Isabela State University, San Fabian, Echague, Isabela, Philippines
}

\begin{abstract}
The development of Drone-based Geographical Information System (GIS) Mapping of Cassava Pythoplasma Disease (CPD) for Precision Agriculture is intended to detect Cassava Phytoplasma Disease. Cassava phytoplasma disease (CPD) is a major danger to the country's cassava sector right now. The Philippines is one of the Asian countries that grow cassava as an agricultural commodity. This initiative delivers unique solutions to help Cassava farmers in the region solve their challenges. The researchers developed the system using the Rapid Application Development (RAD) Methodology as a guide. The system's process flow was conceptualized using Data Flow Diagramming. The methods used in the detection process are Pixel Intensity, Color Intensity, and Ratio and Coordinates Plotting using Raw Data and Featured Layer. The development of the Drone-based Geographical Information System (GIS) Mapping of Cassava Pythoplasma Disease (CPD) for Precision Agriculture is an effective and innovative tool in detecting CPD in order to prevent the spread of the disease. The implementation of the developed system addressed the current needs of the partner agency in monitoring and preventing the occurrence of the CPD in their cassava plantation. Visual Imaging of CPD Heat Map Using Arc GIS JavaScript API was an effective tool in detecting the presence of Cassava Phytoplasma disease in cassava plantation using the different techniques and methodologies
\end{abstract}

Keywords - ARC GIS, Heat Map, JAVA Script, Visual Imaging, Web-based system.

\section{INTRODUCTION}

Cassava (Manihot esculenta Crantz), a continuous plant that is one of the world's top food crops and feed plants in a subtropical and tropical landmass like Asia, mostly produced by farmers with little resources [1]. Cassava is one of the important agricultural crops also in the Philippines. It has a wide range of industrial applications, including flour, starch, and bio-ethanol.
Cassava has developed as a versatile crop for the twentyfirst century, one that answers to the needs of developing nations, global economic trends, and climate change issues. Cassava phytoplasma disease (CPD) is a massive threat to the country's cassava sector right now. The Philippines is one of the Asian countries that cultivates cassava as one of its agricultural crops. The Cassava is sold to Feeds Manufacturing Industries by the Cassava farmers for feeds processing as hog raiser, and fishpond owners consume. It is also used as a commodity such as flour and alternative food for rice in some areas in the Philippines [2]. Although there is a growing demand for Cassava Production in the Philippines, the Cassava Farmers are hesitant to invest in growing Cassava because of the existence of Cassava Phytoplasma Disease (CPD). The CPD became the Cassava Farmers' major problem. When CPD symptoms show four to six months after planting or in the midst of the planting season, the presence of CPD in their crop reduces Cassava yields by roughly 50 percent to 70 percent. When infection occurs during the first three months after planting, the yield might be decreased to zero. CPD, which is becoming more common and spreading across the country, poses a danger to cassava supplies, despite the significant demand for food, feed, and industrial purposes. Worse, it is expected to reduce export volume by up to $30 \%$, harming the country's 1.5 billion-dollar cassava sector.

As a solution to the problem, this study aims to design, develop and implement a Web-based Visual Imaging of CPD Heat Map using Arc GIS JavaScript API to monitor, mitigate and control the spread of the CPD disease. Specifically, we sought to answer the following specific objectives: (1) Develop the interface of Web-Based Visual Imaging of CPD Heat Map; and (2) Integration of ArcGIS JS API to the Web-Based Visual Imaging of CPD Heat Map. 


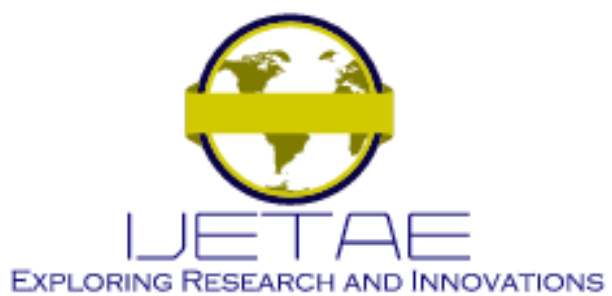

International Journal of Emerging Technology and Advanced Engineering Website: www.ijetae.com (E-ISSN 2250-2459, Scopus Indexed, ISO 9001:2008 Certified Journal, Volume 12, Issue 02, February 2022)

The expected outputs of this project focused on the application of the developed system used in Visual Imaging of Cassava Phytoplasma Disease (CPD) Heat Map using ArcGIS JavaScript API; Establish a visualization method for CPD through Heat Map using ArcGIS JavaScript API; and Identification of CPD disease using heat map based on the degree of severity of the disease in Cassava.

\section{LITERATURE REVIEW}

The integration of technologies in mapping the Cassava Pythoplasma Disease (CPD) is very important to come up with an accurate and reliable web-based system. A review of several mapping or geographical information systems (GIS) was established to determine the gaps and arrive at a more innovative system.

GIS refers to computer technology, engaged in at least for use in substantial applications and a new field. Estimates of the size and importance of the GIS market indicate that it is both national and global in scope and that it is rapidly expanding. Three generally held GIS perspectives highlight the significance of map processing, databases, and spatial analysis. GIS development is characterized as a three-stage process that includes resource inventory analysis and management operations [3]. During the early 1990s, spatial information technology was used by New South Wales Agriculture to aid in the management of agricultural crises such as pest and disease outbreaks, bushfires, and floods. GIS, GPS, and remote sensing work together to improve the results of emergency management activities. It describes four case studies in which spatial information systems (SIS) were employed for emergency management, such as Newcastle Disease containment, flood mapping, and fire damage assessment [4].

Geographic Information System (GIS) use in agriculture is a new and significant study subject in agricultural science. GIS has been used in land resource surveying, land resource appraisal, and agricultural resource management analysis. The use of geographic information systems (GIS) in agriculture has grown in depth and popularity since the 1990s. Some study findings have been directly applied to agricultural productivity, yielding significant economic gains [5].

In a study conducted by Chen et al., the deployment of digital agriculture is predicated on accurate and trustworthy agricultural information.
Agricultural information collecting and data acquisition processing is becoming increasingly sophisticated. It is critical to build a portable agricultural information gathering system with a high degree of integration and mobility. It can process data in a one-stop-shop. It can instantaneously record the GPS coordinates of the field, agricultural attribute data, and picture information and send it to the monitoring system through $3 \mathrm{G}$ or GPRS network. In this work, the system supports Android and IOS system mobile phones, Widgets technology, and HTTP communication is technologies are utilized to construct a real-time agricultural information gathering system based on cross-platform mobile GIS [6]. Another research found that in order to ensure the preservation of agricultural features, such as changes in vegetation in any geographic region, the changes must be identified in order to establish a knowledge base. Their study tries to calculate agricultural changes in the Vellore district using LANDSAT pictures from 2003 to 2009 [7].

GIS technology has been used in a variety of sectors to help individuals analyze various types of geographical data and cope with difficult problems. Managers are increasingly conscious of the critical role of location information and such GIS location analysis technology to boost management capacity in the field of agriculture investment project management, which is strongly tied to location. Its success over the last three years has proved that a system can successfully avoid erroneous and duplicate project application phenomena, as well as being favorable to accepting social monitoring by publishing them online using a web map [8]. GIS maps are commonly employed in drone applications. In some circumstances, GIS map data is required to guard against assaults. In Drone security, a recent article provided an encryption technique for GIS map data. The suggested technique is based on GIS map data's geographical properties. Geometric objects are collected from GIS map data to conduct discrete cosine transform selective encryption in the frequency domain. The results of the experiments confirmed that the entire map is modified after encryption [9].

To obtain the results of land suitability, a study used GIS-MCDA (Multi-Criteria Decision Analysis) methods, which used nine criteria (elevation, slope, rainfall, light intensity, temperature, air moisture, type of soil, soil $\mathrm{pH}$, and river) that affect land suitability, and the results will be applied in Geographic Information Systems (GIS) based on the web. 


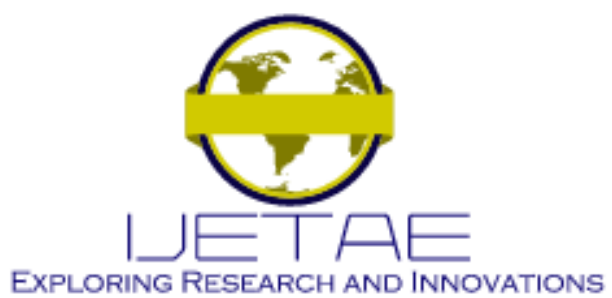

International Journal of Emerging Technology and Advanced Engineering Website: www.ijetae.com (E-ISSN 2250-2459, Scopus Indexed, ISO 9001:2008 Certified Journal, Volume 12, Issue 02, February 2022)

The web-based GIS (Web-GIS) is constructed in accordance with the architectural design [10]. Precision agriculture is now a significant component of drone research initiatives. Agriculture has required commercial drones since the industry's inception, and advanced analytics and software, along with improved drone solutions, have enabled advances. Drones are an important tool in precision agriculture for the future farmer since they allow farmers to monitor crop and livestock status from the air.
The authors investigated drone-assisted approaches such as pesticide sprayer implementation in agriculture and area mapping [5].

From that literature, this paper conducted a research project that uses drone technologies and geographical information systems using a web-based system for mapping CPD in a land area in Isabela. The drone captured images and videos in the land area, which were then fed into a server with web-based applications to map the areas that were affected by CPD.

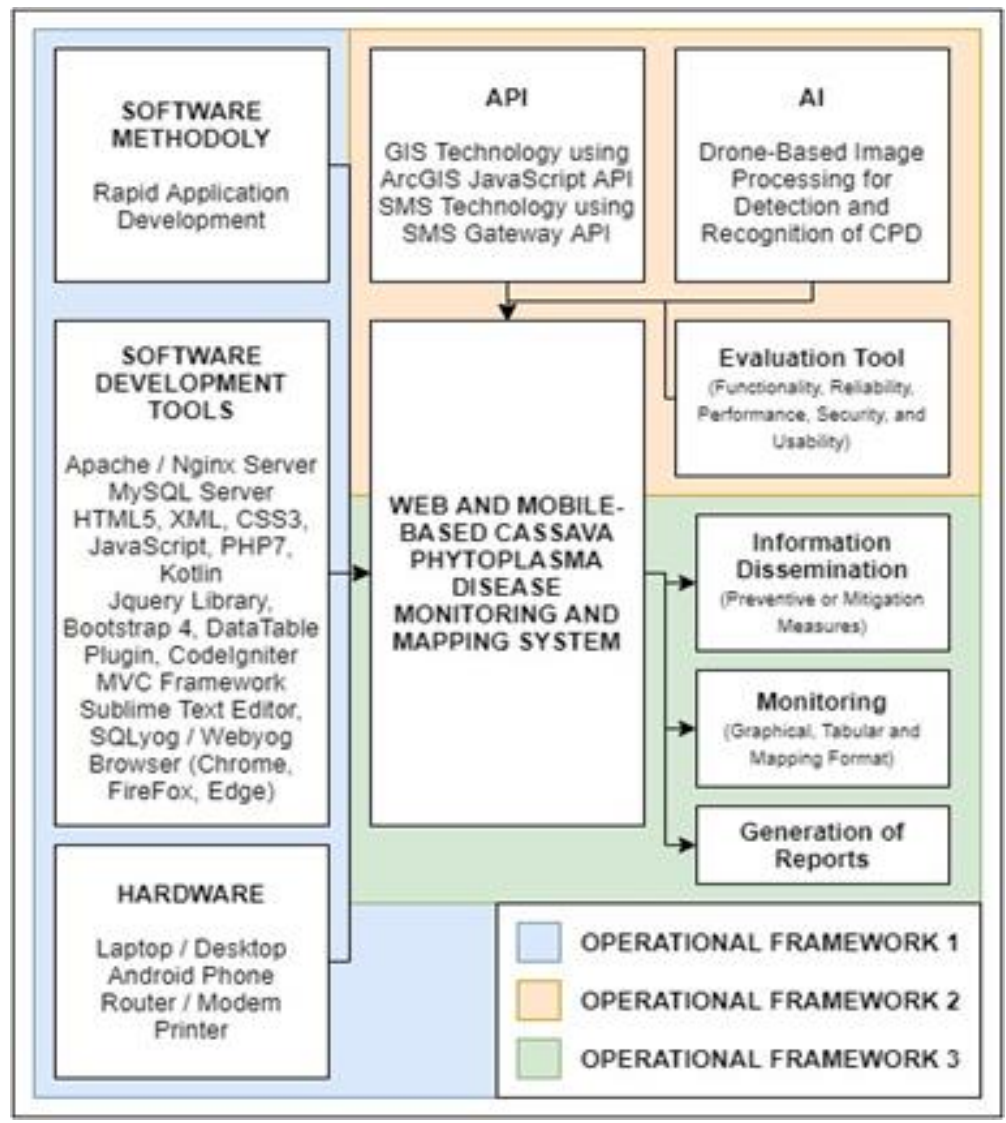

Figure 1. Conceptual Framework of the Study

\section{Methodology}

\section{Conceptual Framework}

Figure 1 shows the architecture of the Web and Mobile Base Cassava Phytoplasma Disease Monitoring and Mapping System, where the Web-based Visual Imaging of CPD Heat Map using Arc GIS JavaScript API serves as its component.
The diagram shows the system development tools, the other components and functionalities of the Information system, software development tools used, evaluation method, and hardware requirements needed for the implementation. 


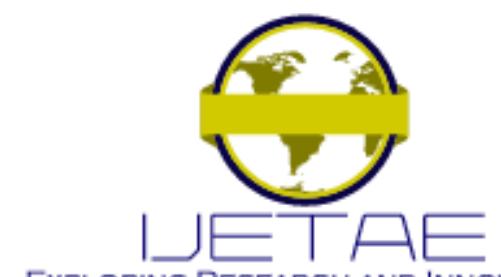

EXPLORING RESEARCH AND INNOVATIONS

\section{International Journal of Emerging Technology and Advanced Engineering}

Website: www.ijetae.com (E-ISSN 2250-2459, Scopus Indexed, ISO 9001:2008 Certified Journal, Volume 12, Issue 02, February 2022)

\section{System Development Methodology}

Figure 2 depicts how the researchers utilized the Rapid Application Development (RAD) Methodology to construct the information system [11].

Figure 2 shows the different phases of the Rapid Application. The different phases are Analysis and quick design, Prototype, Testing, and Implementation.

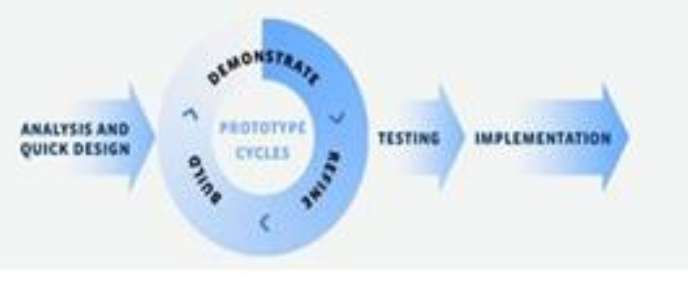

Figure 2. Rapid Application Development Model

\section{Logical Design Tools}

The system's process flow was conceptualized using Data Flow Diagramming.

Figure 3 shows the detailed presentation on the process flow of transactions from the System Administrator, MAO as Monitoring User, Cooperative as Transactional /Management User, Experts as Resource Personnel, and Farmer as Client to the system and vice versa. Also, shows the relationships of the modules and tables of the database.

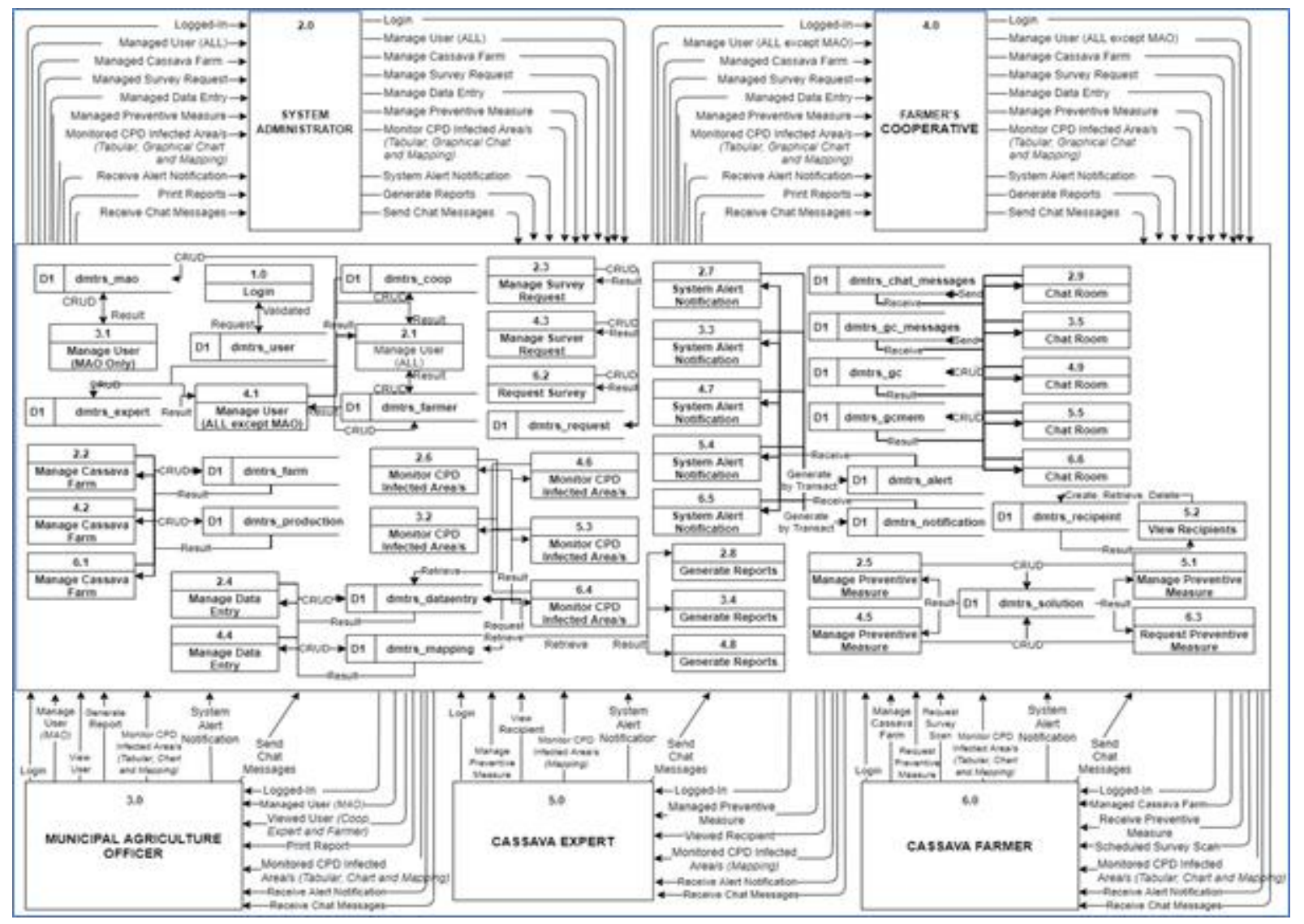

Figure 3. Zero Diagram of the Information System 


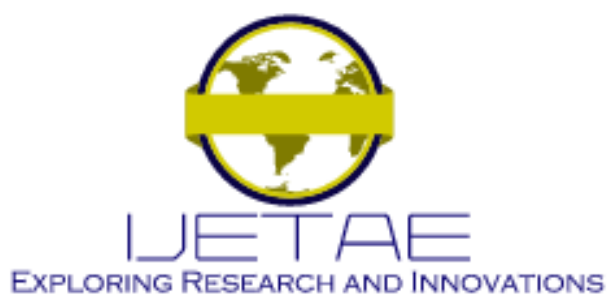

International Journal of Emerging Technology and Advanced Engineering Website: www.ijetae.com (E-ISSN 2250-2459, Scopus Indexed, ISO 9001:2008 Certified Journal, Volume 12, Issue 02, February 2022)

\section{Software Development Tools}

The following were the tools or technologies used in the development of the system.

Apache/Nginx - Software that a Web Server enables the system deployment and implementation.

MySQL Server - A database server that stores all transacted data in the system.

SQLyog - Third-party app for building and maintaining databases with numerical computing, established dependability, ease of use, and flexibility of usage.

Hypertext Preprocessor (PHP 7.1) - A computer programming tool that is used to create the system, particularly its features.

Sublime Text 3 - Text Editor for developing the system's interface and establishing a connection between the system and the server through entirely from scratch.

Emmet - A plugin that allows you to code quickly and properly.

JavaScript - Scripting Language that makes the system interface interactive.

Cascading Style Sheets (CSS3) - Make precise section-wise modifications to increase the system's design flexibility and interaction while also having control over the arrangement.

Hypertext Markup Language (HTML5) / XML - The components used to construct the system's interface.

Ajax (Asynchronous JavaScript and XML) - To ensure that the system is highly stable and does not crash easily, even when the page is heavily loaded, the system functions smoothly until some external program interferes with its operation, such as a hypothetical spam application that is connected to the system when hosted on the internet.

Bootstrap 4 - CSS framework for the system's front-end design.

JQuery 3.7 - JS Library for the system's front-end and back-end, as well as to streamline JavaScript coding.

DataTable 3.7 - Front-end design plugin for tabulating the system's table element.

SweetAlert - Front-end design plugin for customizing and animating the system's popup alert box.

Code Igniter 3.1 - PHP Framework is used to build projects more faster than writing code from scratch, as well as to reduce the amount of code required in a particular activity.

Android Studio 3 - It is an android development IDE that is used to create the system's mobile or android version.
Kotlin - A framework programming language made up of Java that is used for developing android applications.

Browser - software used to test, deploy, and implement the developed system.CodeIgniter

Visual Presentation of Heat Map

Geographical Information System

An Information System called Geographical Information System (GIS) is used for managing information [2]. Geographical Information System deals particularly with geographic or spatial data needing voluminous information to access, manipulate, and provide timely output results. Latitude and longitude coordinates are determined for the geographic data indicating the location of an object or space. Using GIS interpretation of spatial data turning-out easy and simple to understand [12].

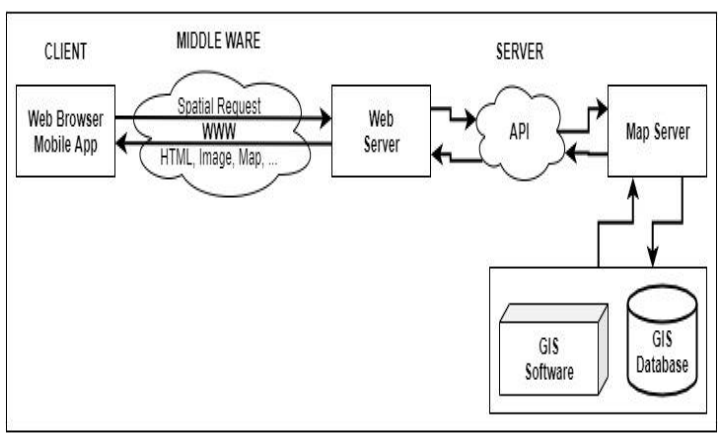

Figure 4. GIS Architecture

Pixel Intensity

Every Map pixel is assigned an intensity value depending on its proximity to one or more points. The points are then plotted coordinates. And all points have a specific field [13]. The field is the queried data containing latitude and longitude coordinates, timestamps, etc., for the basis of the data-driven visualization. If the field is given, the intensity value is multiplied by the field value. The field value is utilized as a multiplier in the heat map, making locations with high field values hotter than those with low field values. And predefining the max and min pixel intensity is a must to apply the color stop of the heat map in the Map, as shown in figure 3.

\section{Color Intensity and Ratio}

The heat map is created by supplying a series of Color Intensity values to the Map renderer [14]. The Color Intensity may identify in linear colors in hexadecimal format, as shown in figure 3 . 


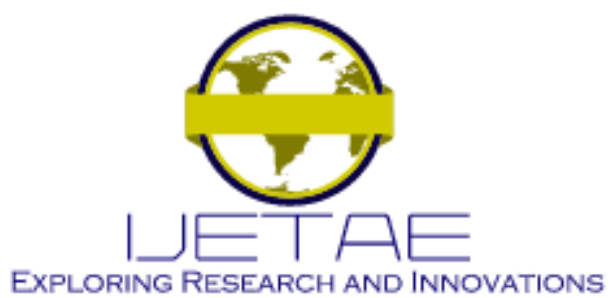

International Journal of Emerging Technology and Advanced Engineering Website: www.ijetae.com (E-ISSN 2250-2459, Scopus Indexed, ISO 9001:2008 Certified Journal, Volume 12, Issue 02, February 2022)

The ratio represents the ratio of the pixel's intensity value. The number of Color Intensity is the number of ratios, and each color has a corresponding ratio value. Both are manually calibrated and predefined depending on the number or range of ratio. The ratio value ranges in decimal numbers 0 to 1 and is not allowed to exceed 1 . It may cause an error in the rendering of the Map.

\section{Coordinates Plotting}

Raw Data

The raw data used contains timestamp and coordinates in text file format. Extraction of the raw data using a process method "file stream" for reading the text file, and exploding or splitting every word from each line of the file to get the coordinates and store it into the dataset collection. The file Stream method is a predefined function in every programming language. It is used to read uploaded files and declare external files through the repository path into the webserver.

\section{Featured Layer}

After the extraction of raw data and the process of collecting dataset storing into the dataset collection array, the feature layers value is the dataset collection array. Feature Layer is the container and the API method for visual presentation of the coordinates in the Map.

\section{Results AND Discussion}

Figure 5 shows the program interface of the developed information system, highlighting the Heat Mapping features of the system.
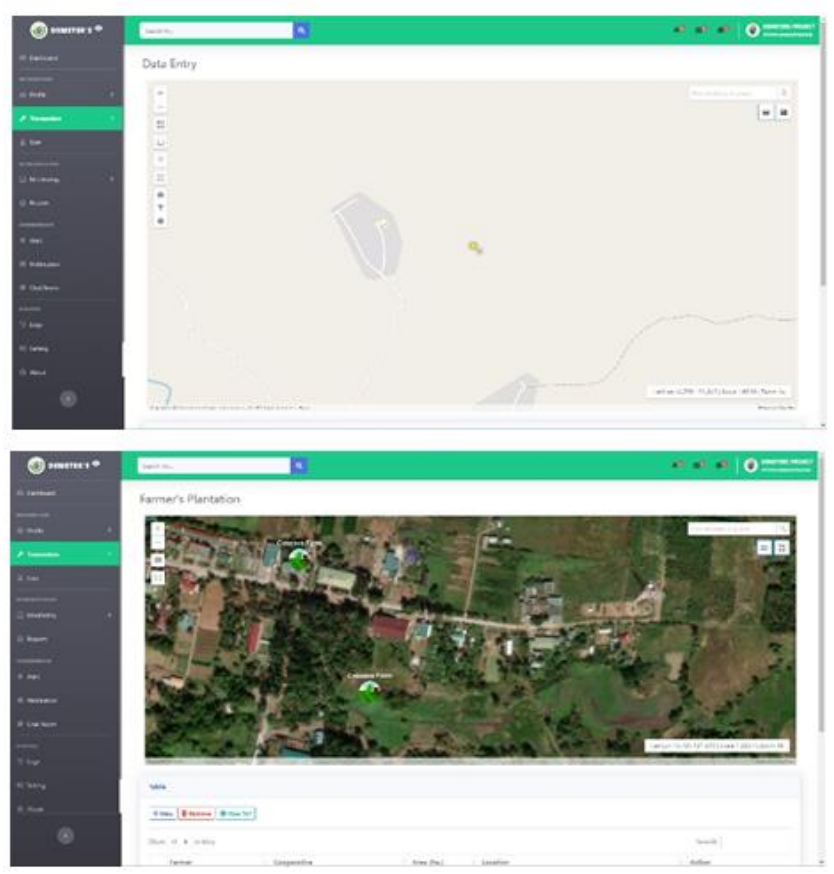

Figure 5. Web-Based CPD Monitoring and Mapping System

Visual Presentation of Heat Map

Source Code

Figure 6 shows the actual source code of the heatmap showing the value of color intensity, ratio, and pixel intensity written in JavaScript.

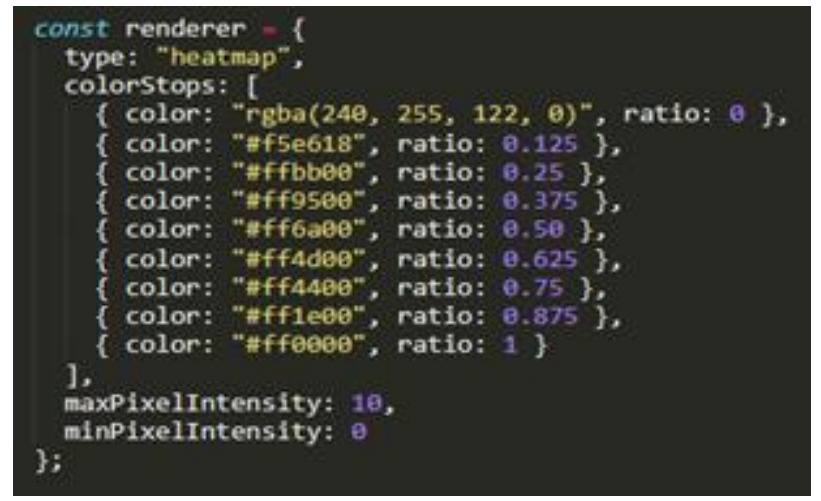

Figure 6. Sample Heat map Source Code 


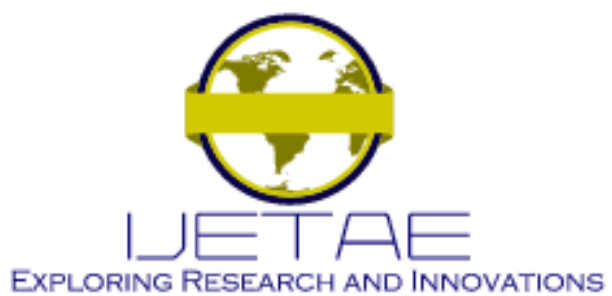

International Journal of Emerging Technology and Advanced Engineering Website: www.ijetae.com (E-ISSN 2250-2459, Scopus Indexed, ISO 9001:2008 Certified Journal, Volume 12, Issue 02, February 2022)

\section{Color Intensity and Ratio result}

Figure 7 shows the result of the execution of the source code using nine color combinations from transparent color to yellow, orange, and red. The application of these colors to identifying the CPD disease in casava varies on the severity of the infection to the cassava plants in the field. Yellow color signifies low infection rate, Orange color moderate infection rate, and Red color for severely infected areas.

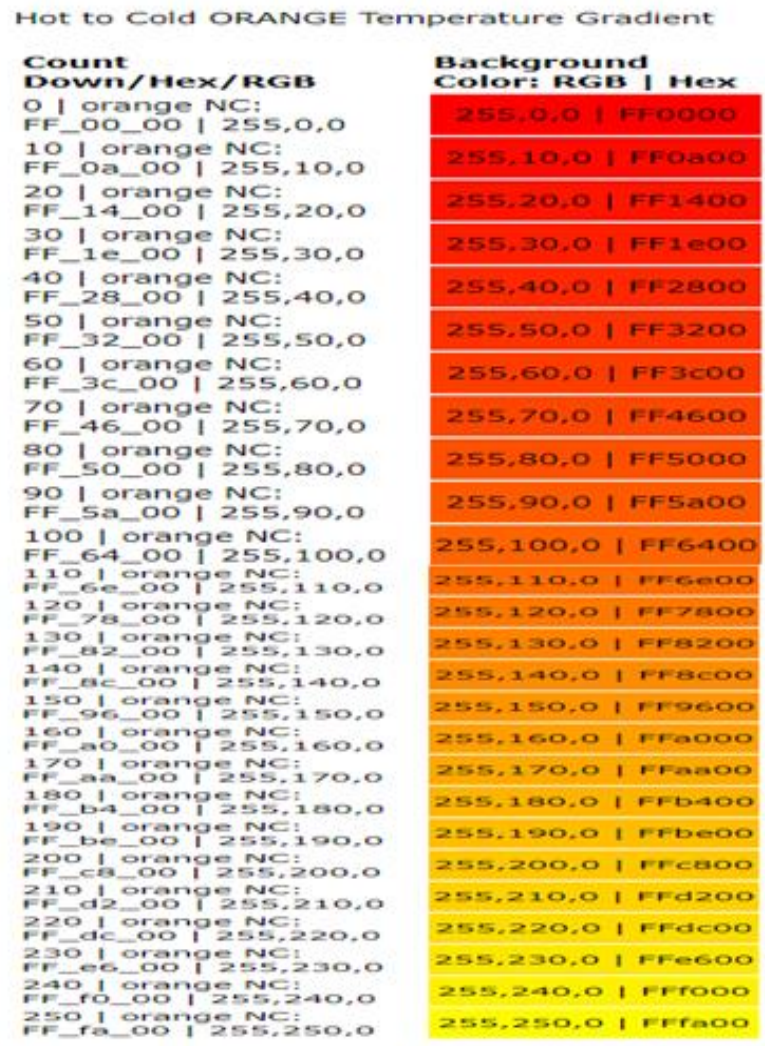

Figure 7. Color Intensity result

\section{Coordinates Plotting}

Actual Raw Data from the drone

Figure 8 shows the actual raw data generated by the drone during a survey. This data was used to specifically determine the exact location of the cassava plantations based on the coordinates inputted by the user.

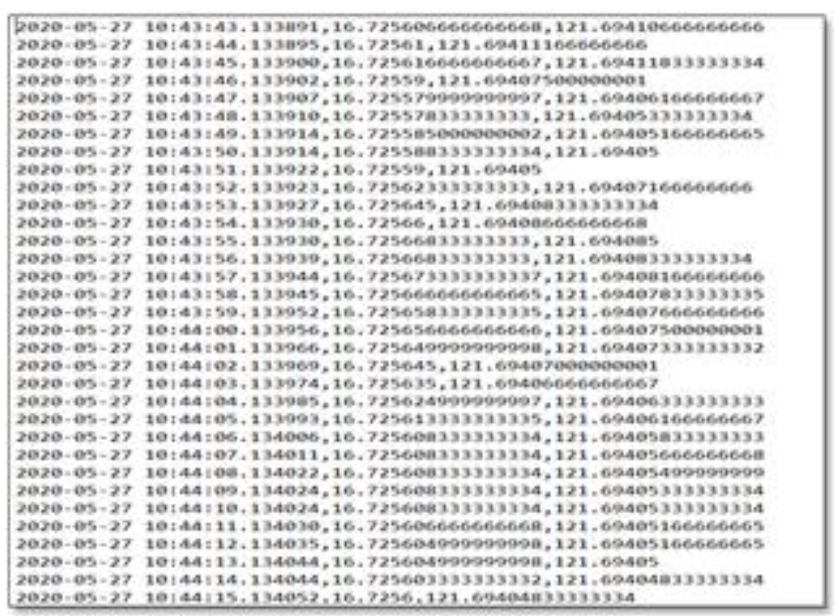

Figure 8. Actual Raw Data

\section{Featured Layer}

Figure 9 shows the actual footage of the Map during the testing at San Guillermo, Isabela. The Cassava Plantation has 5000 cassava stalks planted in an area of around 500sqm. And detected four cassava stalks that CPD infected.

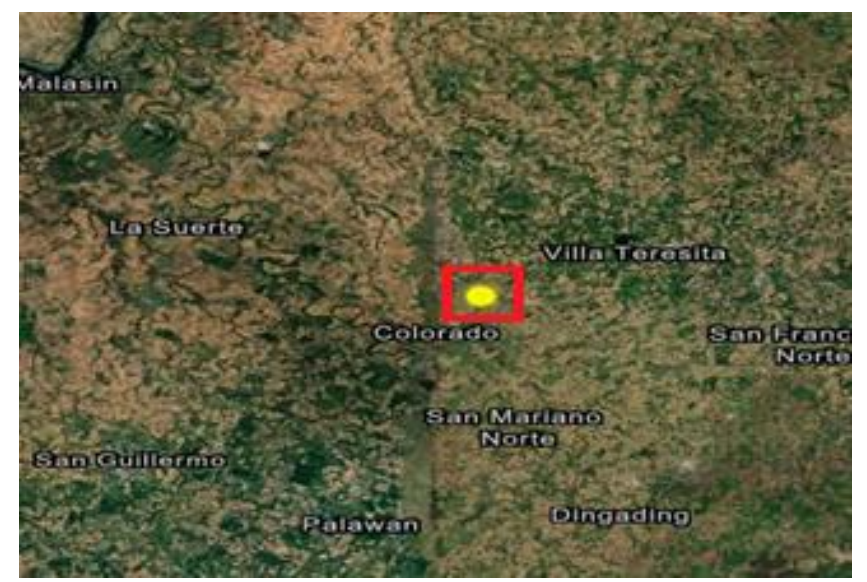

Figure 9. Actual footage of the Map during the testing at San Guillermo, Isabela

Figure 10 shows the details of the mapping for the featured layer. Here, it indicates the farmer's name, location, name of cooperative, crop, variety, stalk, date planted, last uploaded survey, and the number of CPD stalks that were infected. 


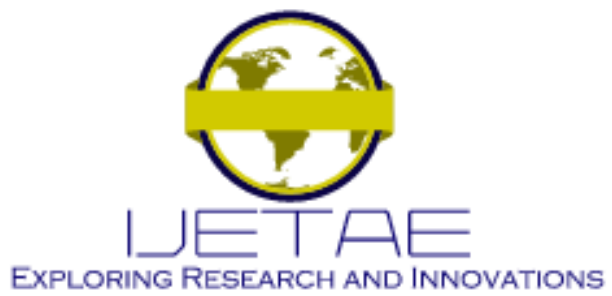

International Journal of Emerging Technology and Advanced Engineering Website: www.ijetae.com (E-ISSN 2250-2459, Scopus Indexed, ISO 9001:2008 Certified Journal, Volume 12, Issue 02, February 2022)

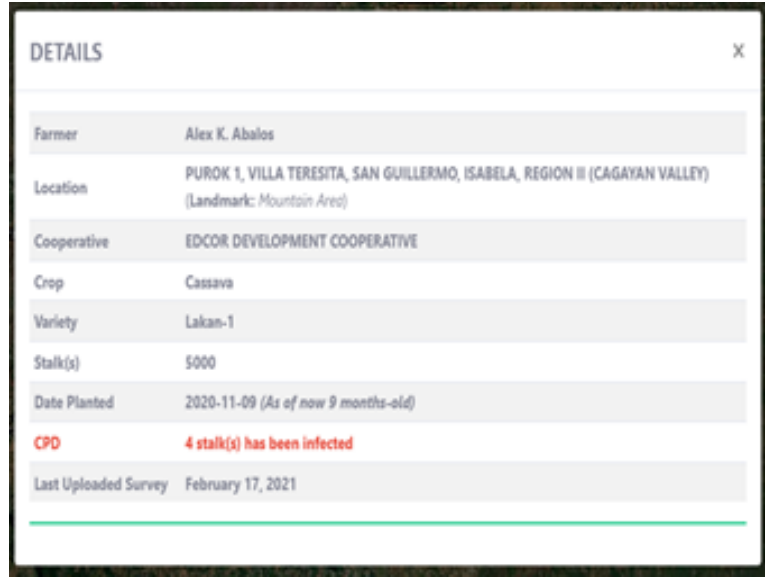

Figure 10. Mapping results details

\section{CONCLUSION}

The development of the Drone-based Geographical Information System (GIS) Mapping of Cassava Pythoplasma Disease (CPD) for Precision Agriculture is an effective and innovative tool in detecting CPD in order to prevent the spread of the disease. The implementation of the developed system addressed the current needs of the partner agency in monitoring and preventing the occurrence of the CPD in their cassava plantation.

Drone-based Geographical Information System (GIS) Mapping of Cassava Pythoplasma Disease (CPD) for Precision Agriculture was an effective tool in detecting the presence of Cassava Phytoplasma disease in cassava plantations using the different techniques and methodologies.

\section{RECOMMENDATION AND FUTURE WORKS}

After several trials and implementation of the system, we found out some things we still need to work on to go with the flow of the fast-paced technologies. To cater to the demands of new technologies, the authors suggest that in future work, the heatmap can be recolored, rescaled, or rotated in a customized manner. Develop a useful toolkit for convenience when visualizing and manipulating heatmaps of CPDs. Furthermore, the graphical user interface of the Web-Based CPD Monitoring and Mapping System may be enhanced for better data visualization quality.

\section{Acknowledgement}

We want to express our heartfelt gratitude to the Department of Science and Technology (DOST) for funding this project as part of the Science for Change Program, specifically the CRADLE PROGRAM, and to the Philippine Council for Agriculture, Aquatic, and Natural Resources Research and Development (PCAARRD), particularly the Agricultural Resources Management Research Division, as the monitoring body (ARMRD). Isabela State University, Quirino State University, EDCOR, and the Isabela LGU San Guillermo.

\section{REFERENCES}

[1] M. A. El-Sharkawy, "Cassava biology and physiology..," Plant Mol. Biol., vol. 56, no. 4, pp. 481-501, 2004, doi: 10.1007/s11103-0052270-7.

[2] I. T. Plata, E. B. Panganiban, B. B. Bartolome, F. E. R. Labuanan, and A. C. Taracatac, "A concept of cassava phytoplasma disease monitoring and mapping system using GIS and SMS technology," Int. J. Adv. Trends Comput. Sci. Eng., vol. 8, no. 6, pp. 3357-3361, 2019, doi: 10.30534/ijatcse/2019/108862019.

[3] D. J. Maguire, "An overview and definition of GIS," Geographical information systems. Vol. 1: principles. pp. 9-20, 1991.

[4] G. J. Tupper et al., "Use of remote sensing and GIS technologies by New South Wales Agriculture for emergency management," Int. Geosci. Remote Sens. Symp., vol. 4, pp. 1489-1491, 2000, doi: 10.1109/igarss.2000.857249.

[5] W. Budiharto, A. Chowanda, A. A. S. Gunawan, E. Irwansyah, and J. S. Suroso, "A Review and Progress of Research on Autonomous Drone in Agriculture, Delivering Items and Geographical Information Systems (GIS)," Proc. 2019 2nd World Symp. Commun. Eng. WSCE 2019, pp. 205-209, 2019, doi: 10.1109/WSCE49000.2019.9041004.

[6] X. Chen, J. Zhao, J. Bi, and L. Li, "Research of real-time agriculture information collection system base on mobile GIS," 2012 1st Int. Conf. Agro-Geoinformatics, Agro-Geoinformatics 2012, pp. 533536, 2012, doi: 10.1109/Agro-Geoinformatics.2012.6311703.

[7] S. Kumar, M. Anouncia, S. Johnson, A. Agarwal, and P. Dwivedi, "Agriculture change detection model using remote sensing images and GIS: Study area Vellore," 2012 Int. Conf. Radar, Commun. Comput. ICRCC 2012, pp. 54-57, 2012, doi 10.1109/ICRCC.2012.6450547.

[8] Z. Ren, Y. Hou, and X. Lu, "A case of GIS application in agricultural project management," 2013 2nd Int. Conf. AgroGeoinformatics Inf. Sustain. Agric. Agro-Geoinformatics 2013, pp. 18-21, 2013, doi: 10.1109/Argo-Geoinformatics.2013.6621871.

[9] G. P. Ngoc, K. S. Moon, S. H. Lee, and K. R. Kwon, "GIS Map Encryption Algorithm for Drone Security Based on Geographical Features," Proc. - 2016 Int. Conf. Comput. Sci. Comput. Intell. CSCI 2016, pp. 1422-1423, 2017, doi: 10.1109/CSCI.2016.0279. 


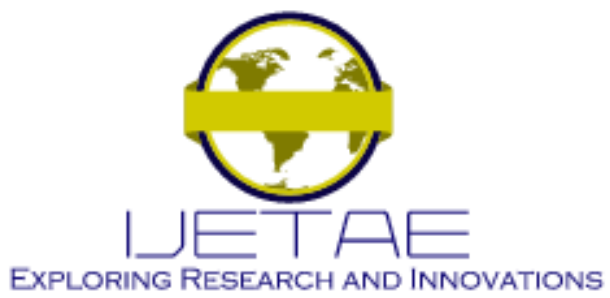

International Journal of Emerging Technology and Advanced Engineering

Website: www.ijetae.com (E-ISSN 2250-2459, Scopus Indexed, ISO 9001:2008 Certified Journal, Volume 12, Issue 02, February 2022)

[10] A. K. Nisyak, F. Ramdani, and Suprapto, "Web-GIS development and analysis of land suitability for rice plant using GIS-MCDA method in Batu city," 2017 Int. Symp. Geoinformatics, ISyG 2017, vol. 2018-Janua, pp. 24-33, 2018, doi 10.1109/ISYG.2017.8280667.

[11] F. R. Labuanan, S.-J. Tapaoan, and R. Camungao, “Application of representation and fitness method of genetic algorithm for class scheduling system,” Int. J. Recent Technol. Eng., vol. 8, no. 2, pp. 1816-1821, 2019.
[12] S. S. Patil, D. R. Kulkarni, and P. D. Patil, "Watershed management for ingrul village in Sangli District, Maharashtra by using GIS," Int. J. Recent Technol. Eng., vol. 8, no. 2, pp. 1593-1599, 2019, doi: 10.35940/ijrte.B2275.078219.

[13] A. A. Alesheik, H. Helali, and H. Behroz, "Web GIS: Technologies and Its Applications," Symposium on Geospatial Theory, Processing and Applications. pp. 1-9, 2002.

[14] W. Deng, Y. Wang, Z. Liu, H. Cheng, and Y. Xue, "HemI: A toolkit for illustrating heatmaps," PLoS One, vol. 9, no. 11, pp. 9-13, 2014, doi: 10.1371/journal.pone.0111988. 